\title{
175 fs-long pulses from a high-power single-mode Er-doped fiber laser at $1550 \mathrm{~nm}$
}

\author{
Parviz Elahi ${ }^{\mathrm{a}, *}$, Hamit Kalaycıŏ̆lu ${ }^{\text {a }}$, Huihui Li $^{\text {a }}$, Önder Akçaalan ${ }^{\text {a }}$, F. Ömer Ilday ${ }^{\mathrm{a}, \mathrm{b}}$ \\ a Department of Physics, Bilkent University, Ankara, 06800, Turkey \\ ${ }^{\mathrm{b}}$ Department of Electrical and Electronics Engineering, Bilkent University, Ankara, 06800, Turkey
}

\section{A R T T I C}

\section{Keywords:}

Ultrafast fiber lasers

Er-Yb fiber amplifiers

Mode-locked fiber oscillators

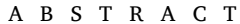

Development of Er-doped ultrafast lasers have lagged behind the corresponding developments in Yb- and Tmdoped lasers, in particular, fiber lasers. Various applications benefit from operation at a central wavelength of $1.5 \mu \mathrm{m}$ and its second harmonic, including emerging applications such as 3D processing of silicon and 3D printing based on two-photon polymerization. We report a simple, robust fiber master oscillator power amplifier operating at $1.55 \mu \mathrm{m}$, implementing chirp pulse amplification using single-mode fibers for diffraction-limited beam quality. The laser generates $80 \mathrm{~nJ}$ pulses at a repetition rate of $43 \mathrm{MHz}$, corresponding to an average power of $3.5 \mathrm{~W}$, which can be compressed down to $175 \mathrm{fs}$. The generation of short pulses was achieved using a design which is guided by numerical simulations of pulse propagation and amplification and manages to overturn gain narrowing with self-phase modulation, without invoking excessive Raman scattering processes. The seed source for the two-stage amplifier is a dispersion-managed passively mode-locked oscillator, which generates a $\sim 40 \mathrm{~nm}$-wide spectrum and 1.7-ps linearly chirped pulses.
\end{abstract}

(C) 2017 Elsevier B.V. All rights reserved.

\section{Introduction}

Due to their practicality, capability to operate stably outside research laboratory conditions, scalability to extremely high average powers and excellent beam quality, fiber lasers continue to attract a lot of attention, resulting in an intense worldwide development. Applications of fiber lasers have been extended to diverse areas such as spectroscopy $[1,2]$, industrial material processing [3], and biomedical applications [4,5]. In particular, material processing with ultrafast pulses offers minimal collateral damage and high precision with the main downsides being slow processing speeds relative to alternative technologies and the complexities arising from using high-energy ultrafast laser systems [6]. To counter some of these disadvantages, ultrafast burst-mode fiber lasers that momentarily achieve high repetition rates have been developed, first with high energies [7-9] and later with high average powers $[10,11]$. Access to high repetition rates have allowed the demonstration of ablation-cooled laser material removal [12]. However, all of these developments, as well as record-breaking performances in terms of pulse energy and average power have been realized with ultrafast Yb-doped fiber lasers operating around $1 \mu \mathrm{m}$ due to the low quantum defect and consequently high pumping efficiency $[13,14]$. On the other hand, several applications stand to benefit from the longer and telecom-compatible wavelength of Er-fiber lasers. These include relatively established and rapidly growing application of multi-photon polymerization [15], which typically uses second-harmonic of the Erlasers, eye-safe remote sensing, which outperforms performance at $1 \mu \mathrm{m}$. In addition, there are exciting developments regarding 3D laser processing of silicon using pulsed Er-fiber lasers [16-19].

To date, power scaling of fiber lasers operating at $1.5 \mu \mathrm{m}$ have encountered several complexity and technical issues mostly arising from high quantum defect, thermal effects and nonlinearity. Consequently, high-power and high-energy ultrafast fiber laser development at $1.5 \mu \mathrm{m}$ has significantly lagged behind the much more rapid progress with $\mathrm{Yb}$ and recently, Tm-fiber lasers, near $1 \mu \mathrm{m}$ and $2 \mu \mathrm{m}$, respectively. Using large mode-area (LMA) fibers in order to overcome nonlinearity, Sobon, et al. demonstrated an Er-Yb co-doped chirped pulse amplification system with $50 \mathrm{MHz}$ repetition rate, generating 835 fs-long compressed pulses at $8.65 \mathrm{~W}$ of average power [20], and Wang, et al. reported 850-fs pulses at $8 \mathrm{~W}$ of average power at a repetition rate of $35 \mathrm{MHz}$ [21]. Using single-mode fibers, Pavlov, et al. reported achievement of $10-\mathrm{W}$ average power at $165 \mathrm{MHz}$ repetition rate with compressed pulse duration of 450 fs [22] and Dai, et al. demonstrated a 3.4-W output average power at $75-\mathrm{MHz}$ repetition rate with compressed pulse duration of $765 \mathrm{fs}$ [23]. In

\footnotetext{
* Corresponding author.

E-mail address: pelahi@fen.bilkent.edu.tr (P. Elahi).
} 


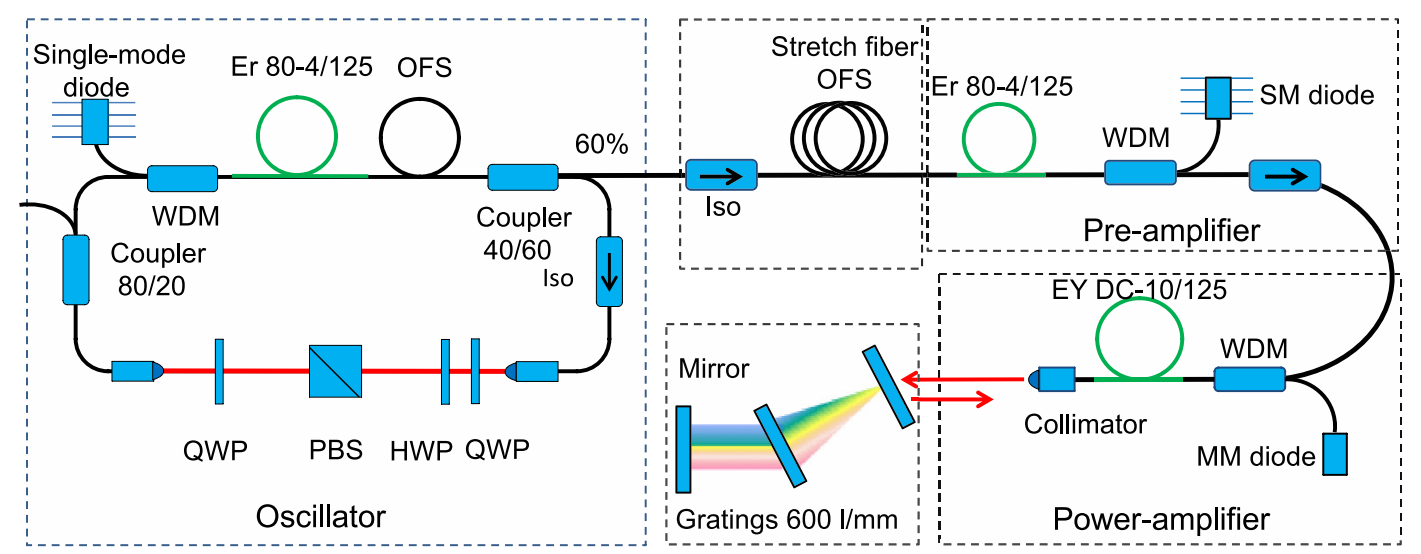

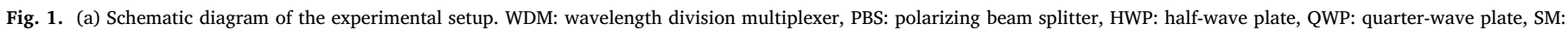
single-mode, MM: multi-mode.

addition to these high-power, MHz-repetition rate lasers, higher-energy lasers operating at $\mathrm{kHz}$ repetition rates were developed using largemode-area Er-Yb co-doped fibers. Morin, et al. achieved $1.5 \mu \mathrm{J}$ pulse energy with 605-fs compressed pulse duration at $300 \mathrm{kHz}$ [24] and Sobon, et al. demonstrated sub-picosecond pulses with energies above 2 $\mu \mathrm{J}[25]$. However, the highest energy levels, by far, have been achieved by X. Peng and colleagues, generating 0.9-mJ pulses with compressed pulse duration of $\sim 500 \mathrm{fs}$, using a special fiber boasting a mode area of $2290 \mu \mathrm{m}^{2}$ and length of only $28 \mathrm{~cm}$, which they referred to as high efficiency gain media [26]. However, all of these sources produced pulse duration in the range of approximately 0.5 to $1 \mathrm{ps}$. There is a lack of high-power sources generating shorter pulses, ideally in the range of 100-200 fs, particularly for the emerging applications discussed above.

Here, we report an all-fiber high-power ultrafast chirped pulse amplifier-laser built of single-mode fiber operating at a central wavelength of $1560 \mathrm{~nm}$. The amplifier has a master-oscillator poweramplifier all-fiber architecture first demonstration for femtosecond pulses in [27] and generates $3.5 \mathrm{~W}$ of average power at $43 \mathrm{MHz}$. The amplified pulses are dechirped with a grating compressor to 175 fs. To our knowledge, these are the shortest pulse durations from a high-power single-mode Er laser-amplifier system comprising only offthe-shelf commercial components, which ensures that it can easily be duplicated by other researchers. Furthermore, the simulation-guided design, that not only balances gain narrowing with Kerr nonlinearity, but even extends it in the last stage of amplification, suggests routes for scaling up to higher pulse energies.

\section{Experiments and results}

\subsection{The dispersion-managed mode-locked oscillator}

Fig. 1 shows the schematic of the experimental setup, which consists of an oscillator followed by two amplifier stages. The oscillator is a 43MHz home-built passively mode-locked dispersion-managed laser cavity designed with the aid of pulse propagation simulation based on the models described in $[28,29]$. The simulation results in Fig. 2(a) indicate more than 2-fold spectral breathing (width from 18 to $39 \mathrm{~nm}$ ) and 20 -fold variation in pulse width ( $90 \mathrm{fs}$ to $1.9 \mathrm{ps}$ ). The passive fiber sections of the cavity consist of a total of $255 \mathrm{~cm}$-long SMF-28 with anomalous dispersion (Corning Inc., $\beta_{2}=-22.8 \mathrm{fs}^{2} / \mathrm{mm}$ at $1550 \mathrm{~nm}$ ), $70 \mathrm{~cm}$-long normal dispersion (OFS Inc., $\beta_{2}=+56.7 \mathrm{fs}^{2} / \mathrm{mm}$ at 1550 $\mathrm{nm}$ ), and $100 \mathrm{~cm}$-long gain fiber with normal dispersion (Er-80-4/125, Thorlabs, Inc., $\beta_{2}=33 \mathrm{fs}^{2} / \mathrm{mm}$ at $1550 \mathrm{~nm}$ and $55 \mathrm{~dB} / \mathrm{m}$ of absorption at 976 ). This combination of fibers yields a slightly positive net cavity group dispersion delay (GDD) of $0.01 \mathrm{ps}^{2}$, similar to [30]. The core and cladding diameters of the gain fiber are $4 \mu \mathrm{m}$ and $125 \mu \mathrm{m}$, respectively. The pump source is a single-mode diode laser centered at $976 \mathrm{~nm}$, and the pump light is coupled to the cavity through a wavelength division multiplexer.

Stable and self starting mode-lock state of the oscillator yields to multi-pulsing when pump power exceeds $320 \mathrm{~mW}$. Hence, the oscillator was operated at $250 \mathrm{~mW}$ pump, for which case the output power from the $60 \%$ port of the $60 / 40$ coupler was $18 \mathrm{~mW}$. The optical spectrum and autocorrelation of the output signals from the oscillator was measured after traversing $1.1 \mathrm{~m}$ of SMF-28 fiber, as shown in Fig. 3(a) and (b), respectively. The spectrum is centered at around $1560 \mathrm{~nm}$ with a fullwidth half-maximum width of $40 \mathrm{~nm}$. The intensity autocorrelation measurement indicates a pulse width of $740 \mathrm{fs}$, assuming a Gaussian pulse shape. These values match the simulation results closely, which predict a pulse width of $1.74 \mathrm{ps}$ and a spectral width of $39 \mathrm{~nm}$ at the oscillator output (shown with the vertical dashed line in Fig. 2(a)), and point to the compression of the apparently positively-chirped pulse following the output, considering the anomalous dispersion of the 1.1 m-long SMF-28 ( $D=18 \mathrm{ps} /(\mathrm{nm} \mathrm{km})$ ). The oscillator's single-pulsed operation and high short term stability are confirmed, respectively, by radio frequency (RF) spectral measurements for 10-GHz scan range at $100-\mathrm{kHz}$ resolution bandwidth (Fig. 3(c)), and its close-up version with 800-Hz span and 10-Hz resolution bandwidth (Fig. 3(d)), which shows a 75-dB signal-to-noise ratio at the fundamental repetition rate.

\subsection{Chirped-pulse amplification}

The amplifier is seeded with 18-mW output signal from the oscillator, which is transmitted through an in-line isolator to protect mode-locking against any back-reflections and then a fiber-based pulse stretcher made of $10 \mathrm{~m}$-long normal-dispersion OFS fiber, where pulses are stretched to $18 \mathrm{ps}$. After the isolator and stretch fiber, the average power drops to $8 \mathrm{~mW}$, due to $20 \%$ loss in the isolator and $40 \%$ SMF-28-to-OFS splice loss as a result of the mismatch between the mode field diameters of the two fiber types (10.4 $\mu \mathrm{m}$ for SMF-28, $6.6 \mu \mathrm{m}$ for OFS). The pulse train is then amplified to $200 \mathrm{~mW}$ with a single-mode pre-amplifier built from 120-cm Er-fiber (Er-80-4/125, Thorlabs, Inc.) pumped by $540 \mathrm{~mW}$, indicating a pump conversion efficiency of $37 \%$. Fig. 4(a) shows the measured optical spectrum at the preamplifier output where the spectral width is narrowed down to $18.5 \mathrm{~nm}$ as a result of gain filtering, while the nonlinearity is too low to fully counteract this effect. The measured autocorrelation signal is presented in Fig. 4(b), which indicates a 7.5 ps-long, largely linearly chirped pulse duration (assuming a gaussian pulse deconvolution factor). The power amplifier comprises of a 140-cm long double-clad Er-Yb co-doped fiber (DCF-EY, CorActive, Inc.) with a $10-\mu \mathrm{m}$ core diameter and a $128-\mu \mathrm{m}$ cladding diameter. The cladding absorption of the gain fiber is $2.4 \mathrm{~dB} / \mathrm{m}$ at $915 \mathrm{~nm}$. A multimode pump-signal combiner was used to deliver pump light from a wavelength-stabilized diode laser (BWT, Inc.) to the cladding 


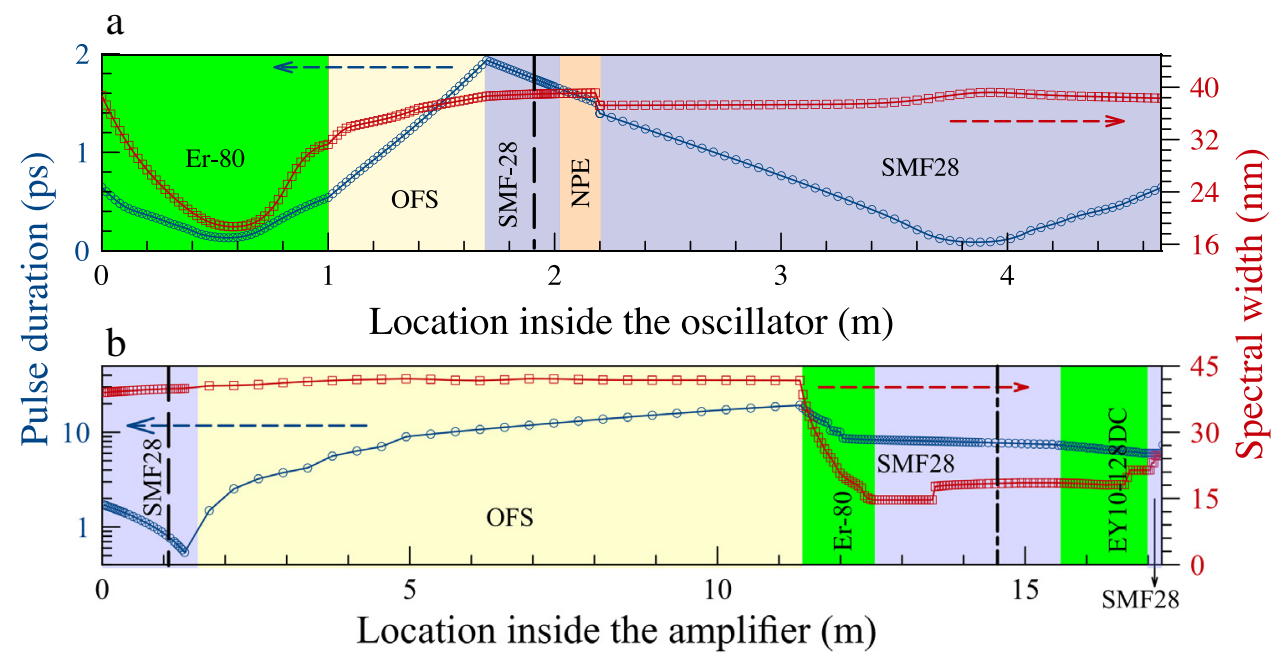

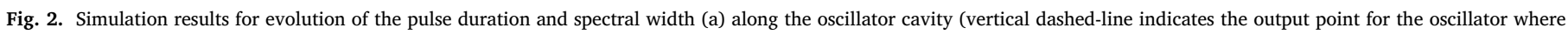

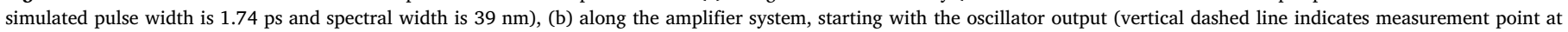
output of the oscillator and the vertical dash-dotted line on the right indicates measurement point at the power amplifier input).

a

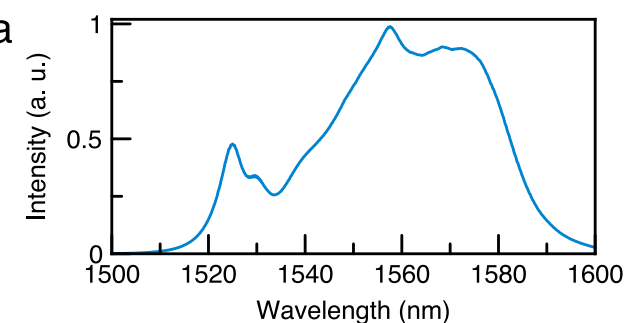

C

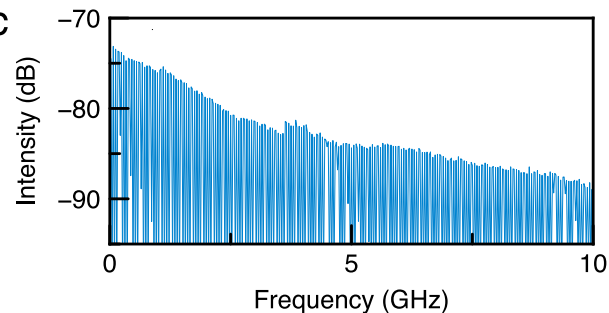

b

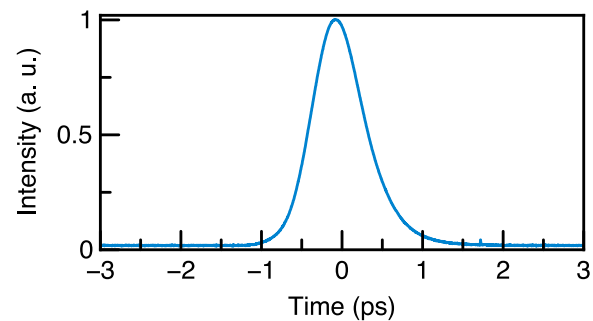

d

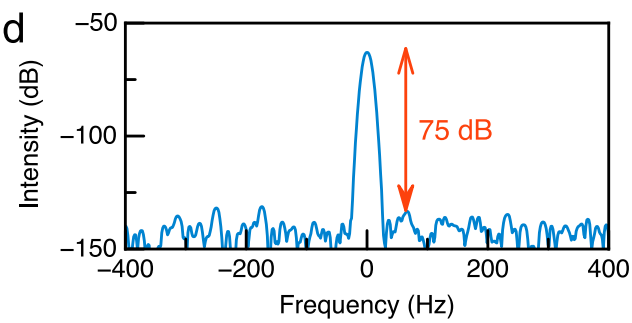

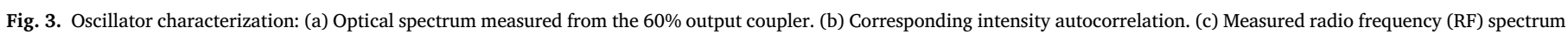

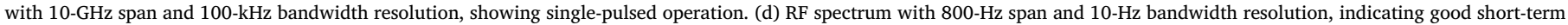
stability. (For interpretation of the references to colour in this figure legend, the reader is referred to the web version of this article.)

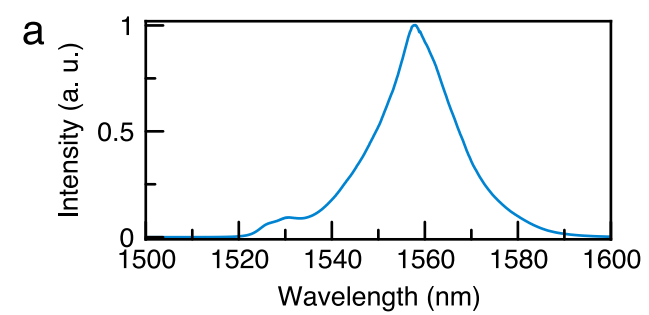

C



b

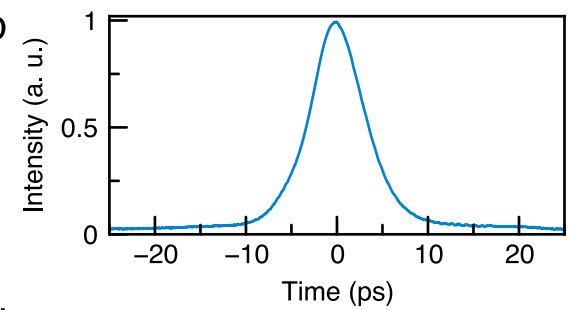

d

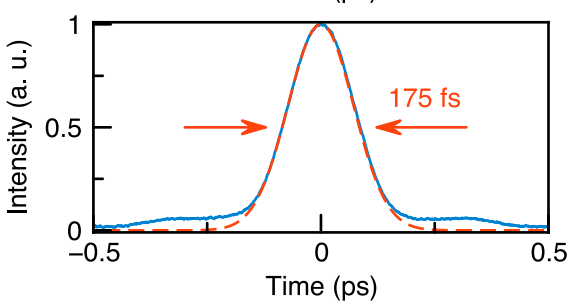



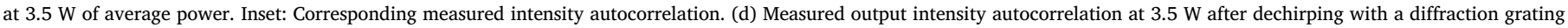

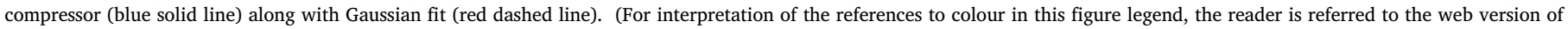
this article.) 
region of the gain fiber. The maximum output power of the pump diode is $18 \mathrm{~W}$.

We achieved $3.5 \mathrm{~W}$ of output power with $13.5 \mathrm{~W}$ of pump power, yielding a pump-to-signal conversion of $26 \%$, where the main limitation on power level is imposed by the onset of the Raman effect. The output beam is strictly single-mode, which is taken from a collimator using SMF-28 as its pigtail fiber, as characterized and reported in [22]. Measured optical spectrum at $3.5 \mathrm{~W}$ of output power is shown in Fig. 4(c). The measured spectral width is about $26 \mathrm{~nm}$ and the center shifts to $1550 \mathrm{~nm}$. The inset of Fig. 4(c) shows the corresponding intensity autocorrelation with 7-ps long temporal width. The pulse propagation simulation results for the amplifier (Fig. 2(b)) predict a spectral width of $40 \mathrm{~nm}$ and a chirped-pulse pulse duration of $1.74 \mathrm{ps}$ at a point of 1.1 $\mathrm{m}$ into the amplifier system, $18.4 \mathrm{~nm}$ and $7.7 \mathrm{ps}$, respectively, at the power amplifier input and $25 \mathrm{~nm}$ and $6.2 \mathrm{ps}$, respectively, at the output of the amplifier, all of which agree closely with the measurement results given above. The simulation results also predict the compression in time at the input of the amplifier due to the positive chirp of the seed pulse and anomalous dispersion of the SMF-28. Furthermore, the narrowing effects of the preamplifier on both the spectrum and pulse width are clearly visible. Finally, the pulses are experimentally compressed to 175 fs using a $300-1 / \mathrm{mm}$ transmission grating pair with an overall efficiency of $56 \%$. Considering the $26-\mathrm{nm}$ spectral width, the compressed duration is about 1.3 times the transform-limited pulse width. We believe this small deviation to arise mainly from the uncompensated third-order dispersion of the grating pair.

\section{Conclusion}

We have demonstrated an ultrafast Er fiber laser-amplifier system able to generate $3.5 \mathrm{~W}$ of average power at the output corresponding to $80-\mathrm{nJ}$ pulses at the $43-\mathrm{MHz}$ repetition rate. The amplifier has an integrated fiber architecture. Compressed pulses with 175 fs width and very clean form have been obtained. The experimental development of the system was guided and verified at each step by numerical simulations of pulse generation in the oscillator and pulse propagation in the amplifier. Importantly, we have demonstrated deliberate use of self-phase modulation to balance gain narrowing in the power amplifier system, which leads to $40 \%$ spectral rebroadening in the last half meter of the system. While the present results are limited by the onset of Raman scattering for the present chirped pulse duration, the use of longer pulses is open, as long as a form of third-order dispersion control is implemented for the grating compressor. In that case, our simulation results suggest the possibility of substantially scaling up the pulse energy, up to at least $1 \mu \mathrm{J}$, without causing the final pulse duration to increase. To the contrary, the amplified bandwidth demonstrated here is capable of supporting $135 \mathrm{fs}$, following higher-order chirp control.

This system generates the shortest pulses at the multi-watt power range for Er-doped lasers, to the best of our knowledge. By virtue of operating at $1.55 \mu \mathrm{m}$, it may find applications in 3D silicon processing or 3D printing based on two-photon polymerization following a secondharmonic generation stage.

\section{Acknowledgments}

This work was funded, in part, by TÜBITAK under the 1001 project numbered 115F098 and the European Research Council (ERC) Consolidator Grant ERC-617521 NLL.

\section{References}

[1] R. Holzwarth, Th. Udem, T.W. Hansch, J.C. Knight, W.J. Wadsworth, P.St.J. Russell, Optical frequency synthesizer for precision spectroscopy, Phys. Rev. Lett. 85 (2000) 2264-2267.
[2] Z. Jiang, C.B. Huang, D.E. Leaird, A.M. Weiner, Optical arbitrary waveform processing of more than 100 spectral comb lines, Nature Photon. 1 (2007) 463-467.

[3] M. Malinauskas, A. Zukauskas, S. Hasegawa, Y. Hayasaki, V. Mizeikis, R. Buividas, S. Juodkazis, Ultrafast laser processing of materials: from science to industry, Light Sci. Appl. 5 (2016) e16133.

[4] J. He, J. Miyazaki, N. Wang, H. Tsurui, T. Kobayashi, Biological imaging with nonlinear photothermal microscopy using a compact supercontinuum fiber laser source, Opt. Express 23 (2015) 9762-9771.

[5] F. Baldini, A. Giannetti, A.A. Mencaglia, C. Trono, Fiber optic sensors for biomedical applications, Curr. Anal. Chem. 4 (2008) 378-390.

[6] K. Sugioka, Y. Cheng, Ultrafast lasers-reliable tools for advanced materials processing, Light: Light Sci. Appl. 3 (2014) e149.

[7] H. Kalaycıoğlu, K. Eken, F.Ö. Ilday, Fiber amplification of pulse bursts up to $20 \mu \mathrm{J}$ pulse energy at $1 \mathrm{kHz}$ repetition rate, Opt. Lett. 36 (2011) 3383-3385.

[8] H. Kalaycıŏ̆lu, Y.B. Eldeniz, Ö. Akçaalan, S. Yavaş, K. Gürel, M. Efe, F.Ö. Ilday, 1 $\mathrm{mJ}$ pulse bursts from a Yb-doped fiber amplifier, Opt. Lett. 37 (2012) 2586-2588.

[9] H. Kalaycıŏ̆lu, Ö. Akçaalan, S. Yavaş, Y.B. Eldeniz, F.Ö. Ilday, Burst-mode Yb-doped fiber amplifier system optimized for low-repetition-rate operation, J. Opt. Soc. Amer. B 32 (2015) 900-906.

[10] P. Elahi, S. Yilmaz, Y.B. Eldeniz, F.Ö. Ilday, Generation of picosecond pulses directly from a $100 \mathrm{~W}$, burst-mode, doping-managed Yb-doped fiber amplifier, Opt. Lett. 39 (2014) 236-239.

[11] S. Yilmaz, P. Elahi, H. Kalaycıŏ̆lu, F.Ö. Ilday, Amplified spontaneous emission in high-power burst-mode fiber lasers, J. Opt. Soc. Amer. B 32 (2015) 2462-2466.

[12] C. Kerse, H. Kalaycıŏ̆lu, P. Elahi, S. Yavas, D.K. Kesim, Ö. Akçaalan, B. Cetin, B. Öktem, M.D. Asik, H. Hoogland, R. Holzwarth, F.Ö. Ilday, Ablation-cooled material removal with ultrafast bursts of pulses, Nature 537 (2016) 84-88.

[13] M.E. Fermann, I. Hartl, Ultrafast fibre lasers, Nature Photon. 7 (2013) 868-874.

[14] C. Jauregui, J. Limpert, A. Tünnermann, High-power fibre lasers, Nature Photon. 7 (2013) 861-867.

[15] E. Kabouraki, A.N. Giakoumaki, P. Danilevicius, D. Gray, M. Vamvakaki, M. Farsari, Redox multiphoton polymerization for 3D nanofabrication, Nano Lett. 13 (2013) 3831-3835.

[16] O. Tokel, A. Turnali, G. Makey, P. Elahi, T. Çolakolu, E. Ergecen, Ö. Yavuz, R. Hübner, M.Z. Borra, I. Pavlov, A. Bek, R. Turan, S. Tozburun, S. Ilday, F.Ö. Ilday, Inchip microstructures and photonic devices fabricated by nonlinear laser lithography deep inside silicon, Nature Photon. (2017) (in press).

[17] I. Pavlov, O. Tokel, S. Pavlova, V. Kadan, G. Makey, A. Turnali, Ö. Yavuz, F.Ö. Ilday, Femtosecond laser written waveguides deep inside silicon, Opt. Lett. 342 (2017) 3028-3031.

[18] M. Chanal, V.Y. Fedorov, M. Chambonneau, R. Clady, O. Uteza, S. Tzorkzakis, D. Grojo, Exceeding the bulk modification threshold of silicon with hyper-focused infrared femtosecond pulses, in: European Conference on Lasers and Electro-Optics European Quantum Electronics Conference, Optical Society of America, 2017 paper CM-8-1.

[19] H. Kämmer, G. Matthäus, S. Nolte, M. Chanal, O. Uteza, D. Grojo, In-volume structuring of silicon using ultrashort laser pulses, in: Lasers in Manufacturing Conference, German Scientific Laser Society, 2017 paper We-2-4.

[20] G. Sobon, P.R. Kaczmarek, D. Sliwinska, J. Sotor, K.M. Abramski, High-power fiberbased femtosecond CPA system at $1560 \mathrm{~nm}$, IEEE J. Sel. Top. Quantum Electron. 20 (2014) 492-496.

[21] H. Wang, L.V. Kotov, D.A. Gaponov, A. Cabasse, M.V. Yashkov, D.S. Lipatov, M.E. Likhachev, J.-L. Oudar, G. Martel, S. Fevrier, A. Hideur, Dissipative soliton generation and amplification in erbium-doped fibers operating at $1.55 \mu \mathrm{m}$, IEEE J. Sel. Top. Quantum Electron. 20 (2014) 283-289.

[22] I. Pavlov, E. Ilbey, E. Dülgergil, A. Bayri, F.Ö. Ilday, High-power high-repetition-rate single-mode Er-Yb-doped fiber laser system, Opt. Express 20 (2012) 9471-9475.

[23] W. Dai, Y. Song, B. Xu, A. Martinez, S. Yamashita, M. Hu, C. Wang, High-power sub-picosecond all-fiber laser source at $1.56 \mu \mathrm{m}$, Chin. Opt. Lett. 12 (2014) 111402.

[24] F. Morin, F. Druon, M. Hanna, P. Georges, Microjoule femtosecond fiber laser at $1.6 \mu \mathrm{m}$ for corneal surgery applications, Opt. Lett. 34 (2009) 1991-1993.

[25] G. Sobon, P. Kaczmarek, A. Gluszek, J. Sotor, K.M. Abramski, $\mu$ J-level, kHz-repetition rate femtosecond fiber-CPA system at $1555 \mathrm{~nm}$, Opt. Commun. 347 (2015) 8-12.

[26] X. Peng, K. Kim, M. Mielke, S. Jennings, G. Masor, D. Stohl, D. Churin, Monolithic fiber chirped pulse amplification system for millijoule femtosecond pulse generation at $1.55 \mu \mathrm{m}$, Opt. Express 22 (3) (2014) 2459-2464.

[27] F.Ö. Ilday, H. Lim, J. Buckley, F.W. Wise, Practical, all-fiber source of high-power, 120 -fs pulses at 1 micron, Opt. Lett. 28 (2003) 1362-1365.

[28] P.K. Mukhopadhyay, K. Özgören, L. Budunoglu, F.Ö. Ilday, All-fiber low-noise highpower femtosecond Yb-fiber amplifier system seeded by an all-normal dispersion fiber oscillator, IEEE J. Sel. Top. Quantum Electron. 15 (2009) 145-152.

[29] B. Oktem, C. Ülgüdür, F. Ömer Ilday, Soliton-similariton fibre laser, Nature Photon. 4 (2010) 307-311.

[30] K. Tamura, E.P. Ippen, H.A. Haus, L.E. Nelson, 77-fs pulse generation from a stretched-pulse mode-locked all-fiber ring laser, Opt. Lett. 18 (1993) 1080-1082. 